\title{
Interactions of virulent and avirulent Yersinia ruckeri strains with isolated gill arches and intestinal explants of rainbow trout Oncorhynchus mykiss
}

\author{
E. Tobback ${ }^{1, *}$, K. Hermans ${ }^{1}$, A. Decostere ${ }^{1}$, W. Van den Broeck ${ }^{2}$, F. Haesebrouck ${ }^{1}$, \\ K. Chiers ${ }^{1}$
}

${ }^{1}$ Department of Pathology, Bacteriology and Avian Diseases, and ${ }^{2}$ Department of Morphology,
Faculty of Veterinary Medicine, Ghent University, Salisburylaan 133, 9820 Merelbeke, Belgium

\begin{abstract}
Yersinia ruckeri is the causative agent of enteric redmouth disease leading to significant losses in salmonid aquaculture worldwide. Little information is available on the pathogenesis of this disease. Basic steps in the establishment of an infection include attachment to the epithelium followed by invasion at the portal of entry. In this study, the interactions of Y. ruckeri with the gills and the gut of rainbow trout Oncorhynchus mykiss (Walbaum, 1792) were studied using standardized perfusion models. Virulent and avirulent $Y$. ruckeri isolates appeared to adhere to and invade both tissues without significant differences. For the first time, the gill and gut perfusion models are shown to be suitable to study bacterial invasiveness.
\end{abstract}

KEY WORDS: Yersinia ruckeri · Adhesion · Invasion · Gill · Gut

\section{INTRODUCTION}

Yersinia ruckeri is the causative agent of enteric redmouth disease (ERM) and causes significant losses in salmonid aquaculture worldwide. Despite the importance of ERM, the precise pathogenic mechanisms of Y. ruckeri are not well understood. A comprehensive understanding of the pathobiology of the infection is required for the rational design of vaccines and other preventive measures to combat ERM (Haesebrouck et al. 2004). Basic steps in the establishment of an infection include attachment to the epithelium followed by invasion at the portal of entry. Both the gills and intestinal tract have been suggested as possible routes of entry for Y. ruckeri (Busch \& Lingg 1975, Valtonen et al. 1992, Tobback et al. 2009). Therefore, the interactions of $Y$. ruckeri with the gills and the gut were studied using standardized perfusion models. Virulent and avirulent strains were included to determine whether differences in virulence are related to differences in adherence and invasive capacity.

\section{MATERIALS AND METHODS}

Bacterial strains. The Yersinia ruckeri isolates used in the present study are listed in Table 1 . Stock suspensions were stored at $-70^{\circ} \mathrm{C}$. After thawing, the bacteria were grown overnight at $20^{\circ} \mathrm{C}$ on Colombia agar (Oxoid) with $5 \%$ sheep blood (blood agar). Colonies were picked from the agar plates and grown in nutrient broth (NB; VWR International) for $24 \mathrm{~h}$ at $20^{\circ} \mathrm{C}$. A non-invasive Escherichia coli strain (DH5 $\alpha$ ) was included as a negative control in adhesion and invasion experiments (Parthasarathy \& Mansfield 2009). This strain was cultured in NB for $24 \mathrm{~h}$ at $37^{\circ} \mathrm{C}$. The number of colony forming units (CFU) per ml was determined by plating tenfold serial dilutions on blood agar plates.

Fish. Twenty-two rainbow trout Oncorhynchus mykiss (Walbaum, 1792) of $600 \mathrm{~g}$ average weight were obtained from a fish farm (Gérouville, Belgium) with no history of ERM. The fish were maintained in $1000 \mathrm{l}$ tanks in filtered, recirculated tap water. They were fed 
Table 1. Yersinia ruckeri strains. Virulence and mortality (no. of dead fish/total no. of fish) were determined in an immersion infection model using juvenile rainbow trout (Tobback et al. 2009). Avirulent: no mortality or persistent infection observed (according to Davies 1991). ERM: enteric redmouth disease. NA: no information available

\begin{tabular}{|c|c|c|c|c|c|}
\hline$Y$. ruckeri strain & Origin & Biotype & Serotype & Virulence & Mortality \\
\hline 5 & Oncorhynchus mykiss with ERM, UK, 2001 & 2 & O1a & Virulent & $6 / 20$ \\
\hline 9 & O. mykiss with ERM, UK, 1995 & 2 & O1a & Virulent & $4 / 20$ \\
\hline E842-95 & NA & 2 & O1b & Avirulent & $0 / 20$ \\
\hline $17.00(2-1)$ & O. mykiss & 2 & O1a & Avirulent & $0 / 20$ \\
\hline CCUG 14190 & O. mykiss with ERM, USA & 2 & O1a & Avirulent & $0 / 20$ \\
\hline
\end{tabular}

daily with a commercial diet (Vijver Visvoeder) until $2 \mathrm{~d}$ before the start of the experiments. Swabs were taken from the skin, fins and gills of 2 fish, chosen at random, for microscopic evaluation of external parasites upon arrival. The fish were found to be free of external parasitic infestations.

Gill perfusion model. The gill perfusion model was used as described by Decostere et al. (2002). Briefly, the fish were euthanized and the first 2 or 3 gill arches on both sides were excised. The smaller dorsal part of each gill arch was cut off to remove the nod to prevent from jeopardizing an efficient perfusion. Thereafter, the afferent (ventral) and efferent (dorsal) arteries of the gill arches were cannulated. Each gill arch was suspended separately in an aerated organ bath surrounded by a water jacket at $20^{\circ} \mathrm{C}$ and perfused with Cortland solution + dextran 1\% (MW 500 000, Sigma) (Decostere et al. 2002). Gill arches were incubated for $1 \mathrm{~h}$ at $20^{\circ} \mathrm{C}$ with a suspension of $\sim 10^{8} \mathrm{CFU} \mathrm{ml}{ }^{-1}$. A noninoculated perfused gill arch served as negative control. Thereafter, each gill arch was washed in an excess of phosphate buffered saline (PBS) and cut in half. To study the adhesion capacity, a randomly selected sample was homogenized and the number of CFU g ${ }^{-1}$ gill tissue was determined by plating tenfold serial dilutions of the suspensions on MacConkey agar (Oxoid) plates. A second gill sample was fixed in Carnoy's solution for at least $2 \mathrm{~h}$, dehydrated in an alcoholxylene series, embedded in paraffin wax and further processed for histological and immunohistochemical (IHC) analysis (Tobback et al. 2009). Sections of $5 \mu \mathrm{m}$, mounted on glass slides, were stained with haematoxylin and eosin (H\&E) and Giemsa. For immunohistochemistry, $5 \mu \mathrm{m}$ sections on SuperFrost slides (Sigma-Aldrich) were pretreated by the antigen retrieval technique. Thereafter, slides were incubated with $3 \%$ $\mathrm{H}_{2} \mathrm{O}_{2}$ in methanol to block endogenous peroxidase and were washed once with PBS. Slides then underwent sequential application of $30 \%$ goat serum, primary rabbit anti-Yersinia ruckeri 1/800 antibody (Tobback et al. 2009), biotinylated goat anti-rabbit antibody 1/500 (DakoCytomation), StreptABComplex/horserad- ish peroxidase (DakoCytomation) and finally 3, 3'-diamino benzidine tetrahydrochloride (Sigma-Aldrich), with a wash step in between each application. Sections were counterstained by use of an aqueous-based haematoxylin staining and mounted.

To study the invasion capacity, the perfusion fluid at the efferent artery was collected during infection. The number of Yersinia ruckeri or Escherichia coli present in the collected fluid was determined by plating tenfold serial dilutions on MacConkey agar plates.

Gut perfusion model. The gut perfusion model was used as described by Nematollahi et al. (2005). Briefly, the fish were euthanized, the aorta intestinalis ventralis was cannulated after the pyloric caeca and the cranial and caudal ends were severed. Subsequently, the gut was flushed with $10 \mathrm{ml}$ PBS and a ligature was tied around both the cranial and caudal end. The gut was suspended in an aerated organ bath surrounded by a $20^{\circ} \mathrm{C}$ water jacket and perfused with Cortland solution + dextran $1 \%$ (Nematollahi et al. 2005). For inoculation, $\sim 10^{8} \mathrm{CFU}$ in $0.4 \mathrm{ml}$ PBS were injected inside the lumen of the ligated gut. A gut injected with $0.4 \mathrm{ml}$ PBS served as negative control. The intestines were incubated for $1 \mathrm{~h}$ at $20^{\circ} \mathrm{C}$ and subsequently flushed with $10 \mathrm{ml}$ PBS after removing the ligatures and cut into 3 equal sized pieces. To study the adherence capacity, the proximal, middle and distal gut sections were processed for bacteriological, histological and IHC examination as described for the gill perfusion model.

To determine the invasion capacity, the organ bath fluid was collected following perfusion. The fluid was centrifuged at $1800 \times g$ for $10 \mathrm{~min}$, the pellet was resuspended in distilled water and the number of Yersinia ruckeri or Escherichia coli was determined by plating ten-fold serial dilutions on MacConkey agar plates.

The gill and gut perfusion models were approved by the ethical committee of the Faculty of Veterinary Medicine, Ghent University (EC 2008/117). The experiments were repeated 3 times.

Statistical analysis. Differences in adherence and invasion capacity between the 5 Yersinia ruckeri 
strains were compared for the gill and gut tissue using a one-way ANOVA test. For each strain, differences in adhesion to and invasion of both tissues were examined using the independent-samples t-test. A significance level of 0.05 was accepted.

\section{RESULTS}

\section{Gill perfusion model}

The 5 Yersinia ruckeri strains highly adhered to the gill tissue and significant differences were not observed, whereas Escherichia coli DH5 $\alpha$ showed lower adherence capacity (Table 2). The number of bacterial cells $\left(\log _{10} \mathrm{CFU} \mathrm{ml^{-1 }}\right.$ ) in the perfusion fluid was significantly $(\mathrm{p}<0.05)$ lower for Y. ruckeri CCUG 14190 compared to the virulent strains 5 and 9. E. coli DH5 $\alpha$ was not recovered from the perfusion fluid.

Histopathological changes were not observed in the gill arches immediately after immersion with any of the 5 Yersinia ruckeri strains. Numerous bacteria were found in the mucus of the primary and secondary lamellae after Giemsa and IHC staining of Y. ruckeri inoculated gill arches, independent of the strain used for infection. Moreover, these sections often showed bacteria closely associated with the gill epithelium (Fig. 1a) and some invaded the lamina propria (Fig. 1b).

\section{Gut perfusion model}

The 5 Yersinia ruckeri strains highly adhered to the gut tissue and significant differences were not observed, whereas Escherichia coli DH5 $\alpha$ showed lower adhesion (Table 2$)$. The number of bacterial cells $\left(\log _{10}\right.$ $\mathrm{CFU} \mathrm{m} \mathrm{m}^{-1}$ ) in the organ bath fluid was lower for strains 17.00(2-1) and CCUG 14190 compared to the other $Y$. ruckeri strains; however, this was not significant $(\mathrm{p}>$
0.05). E. coli DH5 $\alpha$ was not recovered from the organ bath fluid.

Histopathological changes were not observed in the gut segments immediately after infection with any of the 5 Yersinia ruckeri strains. IHC staining revealed the presence of $Y$. ruckeri bacteria in the crypts, attached to the villi and within the epithelial layer of gut segments, independent of the strain used for infection (Fig. 2). Few bacteria were also observed in the lamina propria mucosae.

Adhesion to and invasion in gill tissue compared to gut tissue was not significantly different for any Yersina ruckeri strain $(\mathrm{p}>0.05)$.

\section{DISCUSSION}

This is the first time that both perfusion models were used to study bacterial invasiveness. Only Yersina ruckeri strains and not the non-invasive Escherichia coli strain were isolated from the perfusion fluid and organ bath fluid in the gill and gut perfusion model, respectively. These findings demonstrate that both perfusion models are suitable to study bacterial invasion.

Using the gill perfusion model, IHC examination revealed the presence of numerous Yersina ruckeri adhered to the gill mucus and epithelium and within the lamina propria. Bacteria were also isolated from the perfusion fluid, indicating that they invaded the gill tissue. This is in agreement with previous in vivo studies, in which rainbow trout were experimentally infected (Tobback et al. 2009). These findings indicate that the gills are indeed an important portal of entry as has also been reported for other septicaemic fish pathogens such as Vibrio anguillarum and Edwardsiella tarda (Baudin-Laurencin \& Germon 1987, Ling et al. 2001). Gills are highly vascularized, allowing dissemination of the invaded bacteria to other sites of the body.

Table 2. Oncorhynchus mykiss. Bacteriological examination results for gill arches and intestines (posterior, middle and anterior gut were pooled) after exposure to Yersinia ruckeri or Escherichia coli DH5 $\alpha$. Adhesion capacity expressed as number of bacteria ( $\log \mathrm{CFU} \mathrm{g}{ }^{-1}$ ) isolated from gills and intestine. Invasion capacity shown as bacterial titers $\left(\log _{10} \mathrm{CFU} \mathrm{ml}^{-1}\right)$ isolated from the perfusion fluid collected at the efferent gill artery and from the organ bath fluid $1 \mathrm{~h}$ after infection, in the gill and gut perfusion model, respectively. Data are means \pm SE from 3 independent experiments. ND: not detected

\begin{tabular}{|c|c|c|c|c|}
\hline \multirow[t]{2}{*}{ Bacterial strain } & \multicolumn{2}{|c|}{ Gill perfusion } & \multicolumn{2}{|c|}{ Gut perfusion } \\
\hline & Adhesion & Invasion & Adhesion & Invasion \\
\hline$Y$. ruckeri 5 & $6.37 \pm 0.38$ & $4.37 \pm 0.54$ & $6.52 \pm 0.55$ & $3.57 \pm 0.37$ \\
\hline Y. ruckeri 9 & $6.22 \pm 0.64$ & $5.05 \pm 1.03$ & $7.58 \pm 0.32$ & $3.79 \pm 0.15$ \\
\hline Y. ruckeri E842-95 & $6.99 \pm 0.54$ & $3.49 \pm 0.60$ & $6.39 \pm 0.29$ & $3.78 \pm 0.37$ \\
\hline Y. ruckeri 17.00(2-1) & $6.44 \pm 0.65$ & $2.28 \pm 2.02$ & $6.69 \pm 0.38$ & $0.99 \pm 1.71$ \\
\hline Y. ruckeri CCUG 14190 & $5.81 \pm 0.34$ & $0.77 \pm 0.68$ & $6.07 \pm 0.53$ & $1.89 \pm 1.74$ \\
\hline E. coli DH5 $\alpha$ & 4.73 & ND & 4.06 & ND \\
\hline
\end{tabular}



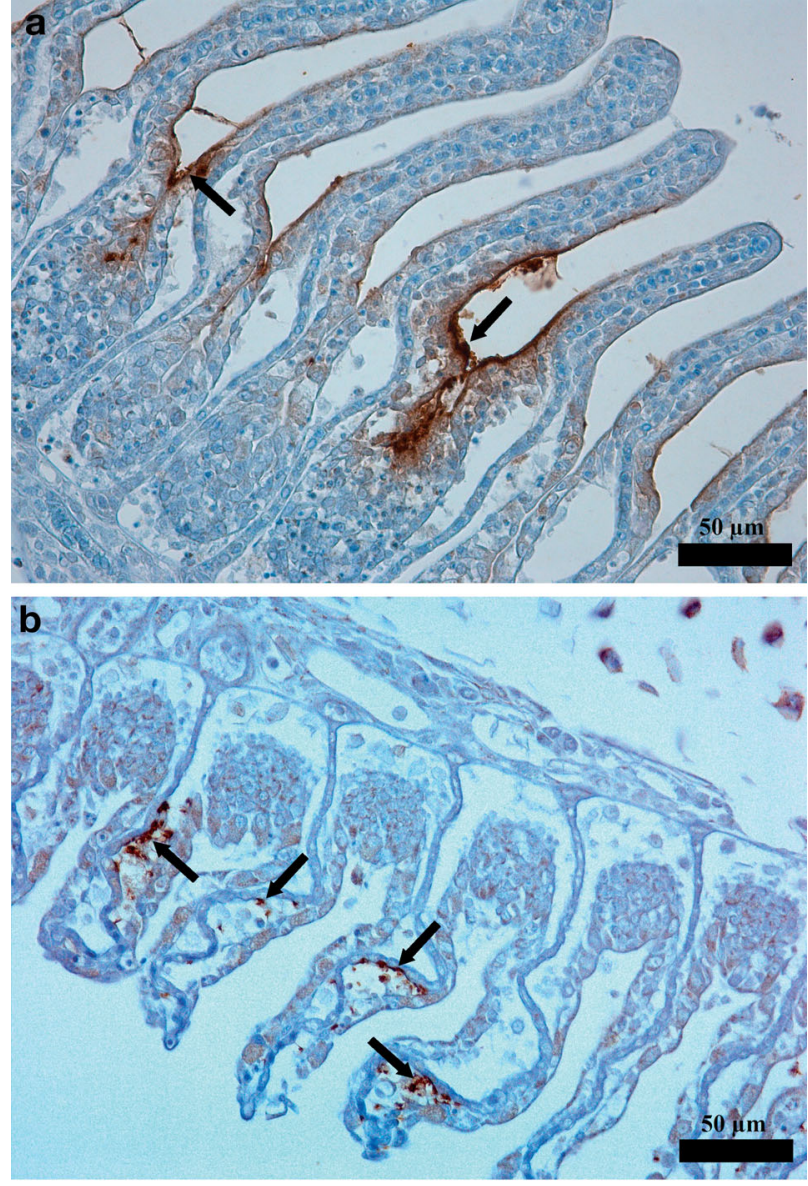

Fig. 1. Oncorhynchus mykiss. Gill arch $1 \mathrm{~h}$ post challenge with Yersinia ruckeri (a) 17.00(2-1) and (b) E842-95. Bacteria either (a) closely associated with the secondary lamellae (arrows) or (b) invaded the lamina propria (arrows). Immunohistochemical staining

A comparative genomic analysis of different Yersinia species by Chen et al. (2010) revealed that the Y. ruckeri chromosome does not appear to result from a reductive evolution from the human enteric yersiniae caused by frameshift mutation. Furthermore, Y. ruckeri apparently lacks conserved metabolic activity found in other bacteria that colonize the intestinal tract; Chen et al. (2010) concluded that Y. ruckeri may use a transmission mode distinct from the enteric pathway. The results of the present and our previous study (Tobback et al. 2009) further support this hypothesis.

Using the gut perfusion model, IHC examination revealed the presence of Yersinia ruckeri adhered to the villi and within the mucosa, and the bacteria isolated from the organ bath fluid indicated that they invaded the gut mucosa. Bacterial translocation from the gastrointestinal tract has also been shown for various other fish pathogens including Vibrio anguillarum and V. alginolyticus (Olsson et al. 1996, Chen et al. 2008).

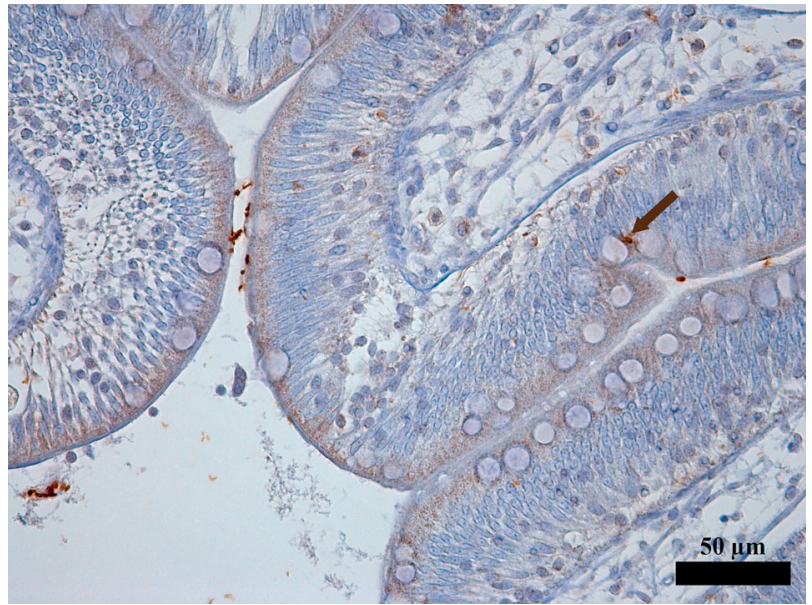

Fig. 2. Oncorhynchus mykiss. Gut explant $1 \mathrm{~h}$ post challenge with Yersinia ruckeri E842-95. Bacteria attached to the mucus and closely associated with the epithelium and within the mucosa (arrow). Immunohistochemical staining

The ability to adhere or invade gill and gut tissue was not significantly different between virulent and avirulent Yersinia ruckeri strains. Likely, other virulence factors such as serum resistance or survival in phagocytes may be important to induce disease (Davies 1991).

Although different perfusion models were applied, both the gill and gut explants were directly exposed to similar numbers of bacteria. Therefore, the results of the gill perfusion model were statistically compared with those of the gut perfusion model. Analysis did not reveal significant differences in adhesion and invasion capacity of any of the Yersinia ruckeri strains between gill and gut tissue. This indicates that at least under our experimental conditions both organs are of equal importance in the initial interaction of $Y$. ruckeri with its host. This is in contrast to our previous in vivo study where lower numbers of bacteria were isolated from the intestine than from the gills of rainbow trout after bath challenge with Y. ruckeri (Tobback et al. 2009). This difference may be due to a different exposure to bacterial cells. Water taken into the mouth of fish is directly forced over the gills, bringing this organ continuously in close contact with the environment. Freshwater fish are reported to drink less than their saltwater counterparts (Bucking \& Wood 2006) and, therefore, the gut may possibly be exposed to a lower bacterial number during immersion infection.

In conclusion, Yersinia ruckeri was shown to colonize and invade gills and gut tissue of rainbow trout. Significant differences in adherence and invasive capacity were not observed between virulent and avirulent strains. 
Acknowledgements: The technical assistance of D. Ameye, C. Puttevils, S. Loomans and M. Foubert is gratefully appreciated. The Institute of Aquaculture (Stirling, Scotland) and the Institut National de la Recherche Agronomique (Paris, France) are acknowledged for providing the Yersinia ruckeri strains 5, 9 and E842-95, 17.00(2-1), respectively, used in this study. The authors thank J. L. Romalde for serotyping these strains. This study was supported by The Research Fund of Ghent University, Belgium, grant no. 01110505.

\section{LITERATURE CITED}

Baudin-Laurencin F, Germon E (1987) Experimental infection of rainbow trout, Salmo gairdneri R., by dipping in suspensions of Vibrio anguillarum: ways of bacterial penetration; influence of temperature and salinity. Aquaculture 67:203-205

Bucking C, Wood CM (2006) Water dynamics in the digestive tract of the freshwater rainbow trout during the processing of a single meal. J Exp Biol 209:1883-1893

Busch RA, Lingg AJ (1975) Establishment of an asymptotic carrier state infection of enteric redmouth disease in rainbow trout (Salmo gairdneri). J Fish Res Board Can 32: $2429-2432$

Chen Q, Yan Q, Wang K, Zhuang Z, Wang X (2008) Portal of entry for pathogenic Vibrio alginolyticus into large yellow croaker Pseudosciaena crocea, and characteristics of bacterial adhesion to mucus. Dis Aquat Org 80:181-188

Chen PE, Cook C, Stewart AC, Nagarajan N and others (2010) Genomic characterization of the Yersinia genus. Genome Biol 11:R1, doi:10.1186/gb-2010-11-1-r1

Davies (1991) Virulence and serum resistance in different

Editorial responsibility: David Bruno,

Aberdeen, UK clonal groups and serotypes of Yersinia ruckeri. Vet Microbiol 29:289-297

> Decostere A, Henckaerts K, Ducatelle R, Haesebrouck F (2002) An alternative model to study the association of rainbow trout (Oncorhynchus mykiss L.) pathogens with the gill tissue. Lab Anim 36:396-402

> Haesebrouck F, Pasmans F, Chiers K, Maes D, Ducatelle R, Decostere A (2004) Efficacy of vaccines against bacterial diseases in swine: What can we expect? Vet Microbiol 100: $255-268$

> Ling SHM, Wang XH, Lim TM, Leung KY (2001) Green fluorescent protein-tagged Edwardsiella tarda reveals portal of entry in fish. FEMS Microbiol Lett 194:239-243

Nematollahi A, Decostere A, Ducatelle R, Haesebrouck F, Pasmans F (2005) Development of a gut perfusion model as an alternative to the use of live fish. Lab Anim 39: 194-199

> Olsson JC, Jöborn A, Westerdahl A, Blomberg L, Kjelleberg S, Conway PL (1996) Is the turbot, Scophthalmus maximus (L.), intestine a portal of entry for the fish pathogen Vibrio anguillarum? J Fish Dis 19:225-234

Parthasarathy G, Mansfield LS (2009) Recombinant interleukin4 enhances Campylobacter jejuni invasion of intestinal pig epithelial cells (IPEC-1). Microb Pathog 47: 38-46

Tobback E, Decostere A, Hermans K, Ryckaert J, Duchateau L, Haesebrouck F, Chiers K (2009) Route of entry and tissue distribution of Yersinia ruckeri in experimentally infected rainbow trout Oncorhynchus mykiss. Dis Aquat Org 84:219-228

Valtonen ET, Rintamäki P, Koskivaara M (1992) Occurrence and pathogenicity of Yersinia ruckeri at fish farms in northern and central Finland: Do wild fish serve as a source of infection? J Fish Dis 15:163-171

Submitted: November 19, 2009; Accepted: April 13, 2010

Proofs received from author(s): June 17, 2010 